\title{
México: el estado y la unidad nacional cardenista
}

Durante la década de 30 importantes sectores de la economia mexicana permanecian en manos del capital extranjero (minas, petróleo, energia, transportes, por ejemplo).

La destrucción de la antigua estructura agraria de poder por la Revolución Mexicana no atingió, por lo tanto en la misma medida - o solamente de forma indirecta - al capital estranjero. Además de eso, tuvo una contrapartida directa en la derrota militar de las milicias campesinas - justamente las iniciadoras del proceso revolucionario - por parte de la nueva e incipiente burguesia emergente de la Revolución.

Con un operariado poco consistente y fragmentado por la existencia incluso de organizaciones paralelas el Estado pasará a jugar - sin el apoyo de capas populares de forma estructurada - un papel de creciente relevancia en el sentido de impulsionar el proceso de industrialización.

El gobierno de Cárdenas (1934/40) se vió frente a la necessidad de crear un mecanismo rápido de acumulación de capitales y de lograr mejores condiciones de negociación con las compañias extranjeras. Impedir el reacomodo de fuerzas agrario-exportadoras poderosas antes de 
la Revolución era otra tarea que el régimen de Cárdenas presentaba como relevante.

La consecución de estas necesidades de la nueva burguesía mexicana seria factible a través de la iniciativa del Estado: organizar el movimiento campesino y obrero, subordinando estes grupos al propio Estado.

En verdad, el Estado mexicano contemporáneo se estructuró a raíz del proceso revolucionario iniciado en 1910. A partir de ahí arrancan la originalidad, bien como los factores diferenciales del desarrollo histórico mexicano si comparado, dentro del contexto latinoamericano, con el caso argentino y el brasileño.

En el segundo decenio de este siglo hay dos procesos ręvolucionarios paralelos: la insurrección campesina encabezada por Zapata y Villa y la revolución burguesa dirigida por Madero y Carranza. Hay, por lo tanto, la coincidencia de la intervención política y militar de dos clases diferentes y antagónicas.

Lázaro Cárdenas será entonces, el ápice de un proceso que desde el princípio visaba la estructuración del Estado involucrada con la integración y subordinación de las masas campesinas que habían se enseñado capaces de constituir sus propios ejércitos y movilizar decenas de miles de trabajadores agrícolas, hecho que no ocurrió ni en Argentina, ni en Brasil, donde la estructuración del Estado no involucraba el desarme campesino.

En los años veinte los ejércitos campesinos fueron derrotados militarmente. Después, la desmovilización campesina continuó con la legislación agraria. Esta, sin embargo, fue prácticamente abandanada en la medida en que la derrota campesina dejaba de significar una amenaza para la nueva burguesía que emergía de los eventos revolucionarios. Entonces, por ejemplo, los repartos de tierras se escaseaban y las mejorías salariales beneficiaban a penas ciertos núcleos obreros.

La meta principal de la nueva burguesía era la de estabilizar el régimen a través de la contención y la absorción de todo lo que pudiera conducir a la organización independiente del movimiento campesino y obrero con relación al Estado. Hay que observar aquí, que en comparación con el campesino, el movimiento obrero era en gran medida a penas naciente, de poca expresividad todavía, reflejo de una industrialización de poca envergadura.

Así, ya en los tiempos de Álvaro Obregón presenciamos la existencia de una burocracia sindical organizada, cuya actuación se dirige en el 
sentido de atar el movimiento obrero al Estado (El Partido Laborista y la CROM de Morones y el Partido Agrarista de Soto y Gama fueron instrumentos políticos decisivos de esa sumisión al obregonismo).

Dentro de una perspectiva mundial, el gobierno de Calles (1924-28) coincide con los momentos posteriores a la derrota de la revolución socialista alemana en 1923, y el gobierno de Cárdenas, por su vez, coincide con los efectos de la Crisis Mundial de 1929. Después del golpe sufrido con la Revolución Rusa de Octubre de 1917 y la amenaza de la Revolución Alemana, el capitalismo se estabilizaba a nivel mundial. Así, la estabilización de la Revolución Mexicana se insertaba en la esfera mundial de la "recuperación" del capitalismo.

En los proyectos de esta nueva burguesía estaba efectivamente el desarrollo industrial. Sin embargo, había que impedir el enlace del naciente movimiento obrero con los campesinos que se habían enseñado capaces de formar un ejército revolucionario; había que impedir esta "contaminación" del movimiento obrero, en el sentido de evitarse la ocurrencia de algo semejante a la Revolución Rusa.

Calles, por lo tanto, continuó la política de integración del movimiento obrero en el aparato estatal, proceso en el cual jugaba un papel importantísimo y fundamental la burocratización de sus grupos dirigentes. Asimismo, terminó el reparto de tierras, sobretudo el reparto en forma de ejidos, buscando el desarrollo de una pequeña burguesía agraria a través de la pequena propiedad parcelaria, organizó el Estado y el sistema bancario para afirmarlos como pilares del desarrollo capitalista nacional. Por otro lado, persiguió a la Iglesia por su condición de reagrupamiento político de la oligarquía terrateniente y derrotó a la rebelión cristera. También enfrentó una amenaza de invasión de Estados Unidos (miedo de la expropriación petrolera que era discutida en ciertos sectores del gobierno callista) y reprimió las fuerzas de izquierda. Entonces, se puede concluir que Calles fue afirmando todos los elementos para una estabilización del desarrollo burgués nacional.

Ahora bien, esta "parálisis" de la vertiente burguesa de la revolución en el período de Calles reveló la posibilidad de un reagrupamiento de fuerzas de antiguos remanescentes de la burguesía agraria detentadora del poder político antes de 1910 (la Revolución quitó de esta burguesía el poder político, pero, y el período callista lo revela, no todo el poder económico).

El Censo de 1930 continuaba a revelar datos impresionantes: 13444 terratenientes monopolizaban el $83.4 \%$ del total de la tierra en manos privadas; 668.000 ejidatarios tenian la posesión de tierras que repre- 
sentaban apenas un décimo de lo que estaba en manos de los hacendados; y 2.332 .000 campesinos no poseían tierras (1).

Los datos revelan que una de las eficiencias fundamentales de la Revolución había sido la desmovilización y el desarme campesino, con lo que la derrota campesina y la supremacía de la vertiente burguesa de la Revolución quedaban por demás evidenciados. La dirección burguesa de la Revolución implicaba, por lo tanto, en el recharzo y el abandono de las antagónicas masas campesinas.

Por eso, no es de extrañar el aparecimiento, al final del período callista, de la contrapartida de estos hechos, eso es, un renacimiento de la lucha social: levantamientos campesinos y huelgas obreras que revelaban un peligro para la estabilidad del grupo gobernante. $\mathrm{Y}$ los recuerdos de los campesinos en armas eran todavía muy vívidos y presentes.

Empieza, entonces, a quedar claro para sectores de la burguesía nacional que se afirmaba, que la "Revolución" necesitaba continuar. $Y$ el início del crescimiento de esta tendencia que tendrá en Cárdenas su ápice, está ya visible en la reelección de Obregón (1928). El asesinato de éste era resultante fundamentalmente de la radicalización de este sector de la burguesía, el nacional, dentro del grupo gobernante, que condujo, a la larga, después del Maximato, a la victoria del cardenismo.

Cárdenas encabezaba un sector del grupo gobernante de mayor sensibilidad y más radical: el que queria llevar adelante el proceso revolucionario burgués, inconforme que estaba con la inminencia del estancamiento de la Revolución antes de llegar a sus metas, lo que podería en consecuencia, poner a perderla toda.

El Maximato había revelado el peligro: con la fundación del Par tido Nacional Revolucionario (PNR), éste sólo podía reglamentar hasta cierto punto las disputas entre los diferentes grupos dominantes en choque cuanto a la dirección que debería tomar la Nación. Asimismo, la manipulación, sin concesión, de las masas obreras y campesinas no podía impedir que estas asimilasen a su manera la manipulación, ni detener las luchas de éstas.

Asimismo, el Jefe Máximo afirmaba que se debía terminar con todo reparto agrario y de dar garantías a la propriedad individual de la tierra, de terminar con el apoyo al ejido y de favorecer a la parcela.

(1) - Weil, Nathaniel y Silvia, "La Reconquista de México, Los dias de Lázaro Cárdenas", Problemas Agrícolas e Industriales de México, Vol. VII, n⿳9 4, octobre-diciembre, 1955, p. 228. 
En 1931, surge la primera Ley Federal del Trabajo, que concedia una serie de conquistas laborales a los trabajadores. Pero, al mismo tiempo establecía, una estrecha reglamentación sobre la existencia y el funcionamiento de los sindicatos y sobre las huelgas. La Ley ponía en manos del Estado el derecho de reconocer o desconocer las elecciones y las direcciones sindicales, bien como de reconocer o declarar "inexistentes" las huelgas, en cuyo caso los obreros debían levantar el movimiento. Al mismo tiempo, los conflictos laborales empezaban a pasar por un largo y complicado procedimiento de "conciliación y arbitraje" en el cual el Estado era el árbitro. Así, los sindicatos se convertían en "instituciones semiestatales" con el sometimiento de las burocracias sindicales al Estado. La consecuencia es un choque entre el curso retrocesor de la Revolución y el ascenso de las luchas de obreros y campesinos. La consecuencia directa dentro del P.N.R. se hará visible: crecerá un ala izquierda (declaraciones socialistas, admiración por la Revolución Rusa, etc.), de la cual surgirá el cardenismo.

El grupo cardenista tenía conciencia de que la destrucción del Estado constituído en 1876 y que la destrucción del poder político de la burguesía agraria durante la etapa armada de la Revolución, que no impidió, sin embargo, la recuperación de parte de su poder económico, tornaban necesaria la recomposición del Estado con base en una nueva y efectiva alianza de clases, o mejor, la recomposición del Estado implicaba en una nueva alianza de clases. Seria un auténtico Estado $\mathrm{Na}$ cional con las medidas proteccionistas, inversiones en obras públicas, apoyo al sector privado, todo de acuerdo con las medidas políticas y económicas anticíclicas en voga en el mundo capitalista de entonces. No obstante, la tendencia antiimperialista era bastante fuerte en este grupo, habiendo que tener en cuenta, por otro lado, que la crisis de 1929 dejara debilitado el sistema capitalista mundial.

Ya en su discurso de protesta presidencial Cárdenas había definido al Estado:

"Sólo el Estado tiene un interés general y por eso sólo él tiene una visión de conjunto. La intervención del Estado ha de ser cada vez mayor, cada vez más frecuente y cada vez más a fondo" (2).

Así, Cárdenas aprovechó la coyuntura favorable del momento de la crisis general del sistema capitalista a comienzos de los treintas y la inminencia de la Segunda Guerra Mundial. Este "aprovechamiento" tuvo su

(2) - Discurso de Protesta como Presidente de la República, Estadio Nacional, México, 30/11/1934, in: Ideario Agrarista del Gen. L. Cárdenas, México, Departamiento Agrario, 1935, p. 6. 
expresión más radical en la expropiación petrolera de 1938, con la cual Cárdenas obtenía el apoyo entusiasta de casi toda la población con lo que prácticamente concretizaba su actuación en pro de la Unidad Nacional.

Antes de eso, sin embargo, Cárdenas se instaló en las nuevas movilizaciones campesinas, las impulsó incluso con la entrega de armas ("Entregaré a los campesinos el mauser con el que hicieron la revolución, para que la defiendan, para que defiendan el ejido y la escuela", en el histórico discurso del ejido de Tres Palos, Gro., el 17 de mayo de 1934), para liquidar también el poder económico de los terratenientes y las canalizó em provecho del Estado, en provecho del proyecto de desarrollo nacional que el Estado cardenista propugnaba.

Así, con el atendimiento de reivindicaciones inmediatas de los campesinos, como el reparto de tierras, o dejando en ellos la esperanza de obtener en el futuro la parcela ejidal, obtuvo la adhesión entusiasta de millones de ellos. Obtuvo también el apoyo obrero a través de mejoras salariales y una eficaz política sindical. Después, el proyecto cardenista de desarrollo capitalista independiente obtuvo también el apoyo de la burguesía toda gracias a su política de estímulo a la industrialización y al benefício que el capital obtenía del proceso inflacionario.

El Estado pasa a obtener entonces una enorme capacidad de control social. Cárdenas lo dijo claramente en Monterrey: "El Gobierno es el árbitro y el regulador de la vida social" (3).

Con el proletariado y el campesinado mantenidos en separado evitaba-se que en el proceso de reformas sociales las masas escaparan al control del Estado.

"Gobierno y campesinos; gobierno y obreros; gobierno y maestros harán una sociedad mejor" (4).

Las concesiones a las masas garantizaban, por su vez, ese control.

Conforme observa Arnaldo Córdova:

"Con el Plan Sexenal se había recobrado la herencia ideológica reformista de la Revolución; con la transformación del Partido Na-

(3) - Cárdenas, Lázaro, Ideario Político, México, Ed. Era, 1972. p. 189. También en Townsend, Willian Cameron, Lázaro Cárdenas, demócrata mexicano, México, Biografias Gandesa, 1954, p. 131.

(4) - Cárdenas, Lázaro, Palabras en Guadalupe Xita Oaxaca, 31/03/1937, in: Cárdenas, Lázaro, op. cit. 
cional Revolucionaro en Partido de la Revolución Mexicana se ligaba muy estrechamente a las masas trabajadoras al Estado de la Revolución, organizandolas como una fuerza política en cuyo nombre se íba a gobernar en adelante" (5).

Se observaba igualmente una notable expansión del sector público y de la sindicalización de los burócratas. Al final de su período, el país entero había sido organizado por el Estado, inclusive los empresarios, obligados a pertenecer a las Cámaras correspondientes.

Ya en la gira electoral, en 1934, Cárdenas afirmaba:

"Que los obreros se organicen de acuerdo con su matiz de pensamiento, de acuerdo con sus intereses profesionales, y que igual cosa haga el empresario industrial y el poseedor de la tierra: la lucha económica y social ya no será entonces la diaria e inútil batalla del individuo contra el individuo, sino la contienda corporativa de la cual ha de surgir la justicia y el mejoramiento para todos los hombres" (6).

\section{En febrero de 1936 en Monterrey Cárdenas confirmará:}

"Las clases patronales tienen el mismo derecho que los obreros para vincular sus organizaciones en una estructura nacional" (7).

Carlos Pereyra se refiere a "una política semi corporativa que mantenia separados al proletariado y al campesinado para evitar que en el proceso de reformas sociales las masas escaparan al control del Estado", para concluir luego después que "pocas veces en la história un Estado había obtenido un grado tal de legitimidad y un dominio tan definitivo sobre la vida económica, política e ideológica de un país” (8).

El Estado cardenista cumplió también de forma clara algunas funciones relevantes del Estado ya consideradas clásicas. Así, el proprio Cárdenas se refiere al hecho de que el Estado mexicano busca crear condiciones materiales reales de la produción cuando estas no son criadas por los capitales individuales:

(5) - Córdova, Arnaldo, La política de masas del cardenismo. México, Era, 1974, p. 146.

(6) - La gira del general Lázaro Cárdenas, Secretaria de Prensa y Propaganda del CEN del PNR, México, 1934, p. 33. in: Córdoba, Arnaldo op. cit. pp. $146 / 147$.

(7) - Cárdenas, Lázaro, Los 14 Puntos de la politica obrera presidencial, in: Ideario Político, op. cit. p. 190.

(8) - Pereyra, Carlos, "México: los límites del reformismo", Cuadernos Políticos, México, $\mathrm{n}^{\circ} 1$, julio-septiembre 1974. 
"El gobierno ha fundado instituciones nacionales para atender las necesidades que no pudo ni quiso atender la iniciativa privada" (9).

Lo mismo ocurre con otra función relevante del Estado, la de la determinación y defensa de las relaciones jurídicas generales y particularmente de las relaciones capital-trabajo, a respecto de la cual Octavio Ianni observa que:

"Las estructuras jurídico-políticas del Estado mexicano y el plan económico y social adoptado por el gobierno Cárdenas establecen: las bases doctrinarias y organizativas a partir de las cuales funcionan y prosperan la propiedad privada, el monopolio estatal, el monopolio privado y el sector agrario, compuesto por los ejidos individuales y colectivos" (10).

\section{También aqui Cárdenas es explícito:}

"Por lo demás, conforme a los principios que gobiernan nuestro derecho, el poder público es el mediador en los conflictos que surgen a diario en las relaciones obrero-patronales" (11).

$\mathrm{Y}$ en Monterrey concluyó: "El goberno es el arbitro y el regulador de la vida social" (12).

Cuanto a la función del Estado en referencia quedó famosa la expresión de Gramcsi "en todo el Estado burgués hay un elemento de coerción y legitimación", lo que según Perry Anderson, es un pensamiento no completado.

\section{Anderson dice específicamente:}

... "el Estado burgués 'representa' por definición a la totalidad de la población abstrayéndola de su distribuición en clases sociales, como ciudadanos individuales, e iguales. Es decir, presenta a hombres y mujeres sus posiciones desiguales en la sociedad civil como si fueran iguales en el Estado" (13).

(9) - Cárdenas, Lázaro, in: Ianni, Octavio. El Estado capitalista en la época de Cárdenas, México, Era, 1977, p. 28.

(10) - Ianni, Octavio, op. cit., p. 37.

(11) - L. C. La función del poder público, Alocución a los directores del Centro Patronal de Monterrey, Nuevo León, sobre la acción gubernamental y la lucha obrera, El Nacional, 11/02/1936, in: Ideario Politico op. cit., p. 18.

(12) - Los 14 Puntos de la politica obrera presidencial, Ideario Politico, op. cit., p. 189 .

(13) - Anderson, Perry, "Las Antinomias de Gramsci", Cuadernos Políticos, $n^{\circ} 13$, julio/septiembre de 1977, México, p. 20. 
El Estado cardenista - Cárdenas utiliza siempre el término gobierno - es instancia poderosa y debe funcionar como árbitro de los conflitos sociales. En ese sentdio, presenta todavia, una peculiaridad inerente al Populismo, que es la sobreposición del gobernante al proprio Estado, lo que le permite "bajar" al llano social con palabras paternalistas:

"Por eso mi gobierno viene recomendando a todos los sectores de la República que estén tranquilos, que guarden serenidad, que mantengan su confianza en que la responsabilidad que yo tengo como jefe del Ejecutivo Federal, sigue en pie velando por los intereses de toda la nación, y especialmente por los intereses de la clase trabajadora" (14).

Hasta 1938 la organización del pueblo no estaba todavia consumada dentro de los parámetros corporativistas que iban alcanzando con el pasar del tiempo.

Hasta 1938, era una organización que no se completaba en la medida que hacia falta un eslabón entre pueblo y Estado:

"Apesar de que el gobernante hablada a nombre de la Revolución
y decía gobernar para los trabajadores que la habían hecho, su poder
seguia siendo un asunto privado suyo, mantenido por la violencia,
para provecho suyo y no de la sociedad: (15).

La obra se completa con la transformación del PNR en el PRM, esto es, con la agilitación del partido en el sentido de garantizar la institucionalización del régimen como conducto elaborado de la articulación entre los trabajadores y el Estado.

Recuerde-se que Cárdenas hereda un partido que por su origen puesta en el Maximato no era un partido nacional, sino más bien un organismo receptador de lealtades individuales a caciques y jefes del ejército. Enrique Suarez Gaona llama la atención de que Cárdenas pudo eliminar a Calles como factor político porque tenia la fuerza militar (lealtad de buen número de caciques y jefes militares) y porque se apoyaba en una base popular como resultado de su política sindical y agrarista. Sin embargo, esta situación política reveló claramente el vacio de la ausencia de un partido oficial, de un partido eminentemente nacional. Como

(14) - Cárdenas, Lázaro, Discurso a trabajadores del país cooncentrados en la Plaza de la Constituición, 22/12/1935, in Ideario, op. cit. p. 60.

p. 161 .

(15) - Córdova, Arnaldo, La politica de masas del cardenismo. Era, 1974, 
observa este autor, "el resultado fue la creación de un instrumento de integración nacional no solo organizado, sino políticamente coherente" (16).

De tal importancia fue este ápice de la estructuración política del Estado cardenista que Arnaldo Córdova pudo puntualizar así esta su caracteristica "sui-generis" (dando la impresión de veracidad a la conceptualización hegeliana de la precedencia del Estado a la sociedad):

"La organización de los trabajadores y la transformación consecuente del PNR operó el milagro y el Estado, finalmente, encontró al pueblo que necesitaba para legitimarse en la sociedad mexicana. El pueblo se organizaba y, a su vez, organizaba al Estado: he aquí la sintesis a que daba lugar el esfuerzo político del cardenismo" (17).

Octavio Ianni, por su vez, observa así esta supremacia del Estado frente a la sociedad mexicana:

"Cárdenas pone al Estado en la vanguardia y dirección de la sociedad; y le dice a ésta que esa es su condición de existencia y progreso" (18).

Lo que permite al mismo autor observar, todavia, que... "Se tiene la impresión de que el conjunto del país es organizado por el Estado" (19).

La magnitud de los éxitos de la política de Unidad Nacional puesta en práctica por el cardenismo, involucraba, naturalmente, el espírito de conciliación de clases, proprio del Populismo, y que alcanzó incluso los partidos de izquierda, como el Partido Comunista Mexicano. Claro que la actuación del PCM, fue justamente influenciada por factores externos y por el propio contexto internacional, pero lo cierto es que de una posición de expectativa crítica este partido pasó a brindar su apoyo al régimen cardenista.

Así, por ocasión del conflicto entre Calles y Cárdenas, el PC autorizó la consigna "Ni con Calles, ni con Cárdenas" (20). Después del VII Congreso de la Internacional Comunista en Moscú (1935) la posi-

(16) - Suarez Gaona, Enrique, "Lázaro Cárdenas y el Neutralismo Actual", in: Lázaro Cárdenas, Revista de la Universidad de México, v. XXV, $\mathrm{n}^{\circ} 9$, mayo de 1971 .

(17) - Córdova, Arnaldo, op. cit. p. 161.

(18) - Ianni, Octavio, op. cit., 26.

(19) - Idem, p. 54.

(20) - Velasco, Miguel Ângel, "El PC durante el periodo Cárdenas", in: Lázaro Cárdenas, Testimonios del Fondo (21-22), México, Fondo de Cultura Económica, 1975, p. 32. 
ción del PC cambió. En la Carta que la delegación mexicana al Congreso envió a la dirección del partido en México, se decia que..." la posición falsa del PC lo impidió comprender a tiempo el contenido real de la política de Cárdenas", ... y admite más adelante que se había lanzado "la consigna errónea: 'Ni con Calles, ni con Cárdenas'" (21).

En julio de 1937 fue aprobado el lema de "Unidad a toda Costa". La nueva estrategia fue resultado, segun Miguel Angel Velasco, "no solamente de presiones que las hubo, como las del entonces Secretario General del PC de EEUU, Brodwer, sino de nuestro proprio análisis de la situación del país, no desprovista de fundamento"... (22).

Esta postura hacia parte, naturalmente, de la estrategia del Frente Popular en el PNR. Miguel A. Velasco concluye, caracterizando la postura final del PCM ante el régimen de Cárdenas:

"Entre el PC y el gobierno de Cárdenas se establecieron relaciones de colaboración, principalmente a través de las organizaciones de masas en las que el partido tenía influencia preponderante" (23).

De esta manera, la estructuración del Estado en los marcos de la Unidad Nacional en torno al jefe de gobierno quedaba hecha de forma tan completa que este podia se dar al lujo de amenazar entregar armas a los campesinos y de enveredar por el campo ideológico socialista.

Al insistir en la necesidad de la educación socialista aclaraba que "la educación socialista no tenia como finalidad despertar la lucha de clases sino aumentar la solidariedad entre ellas" (24).

Con la utilización de expresiones retiradas de la terminologia marxista como "lucha de clases", "plusvalia", "acumulación de Capital", "dictadura del proletariado" (25), Cárdenas y su grupo ingresaban en el

(21) - Idem, p. 43. Lyle C. Brown refíere que hasta fines de junio de 1935, después de Cárdenas haber legalizado la existencia del PCM - este tendria denunciado la actitud como demagogia izquierdista - la consigna habia cambiado para el tono intermediario "Con Cárdenas no, con las masas cardenistas, si". Brown, C. Lyle, Los Comunistas y el Regimen de Cárdenas, in: Lazaro Cárdenas, Revista de la Universidad de México, V. XXV, $\mathrm{n}^{\circ}$ 9/mayo de 1971. Karl Michael Schmitt, habla de la consigna "Ni con Cárdenas, ni con Calles, con las masas cardenistas". Schmitt, Karl Michael, Communism in México (a study in political frustration). Austin, University of Texas Press, 1965, p. 16, citado por Lerner, Victoria. História de la Revolución Mexicana (1934-40) - La Educación Socialista, El Colégio de México, 1979. p. 65.

(22) - Velasco, Miguel, op. cit. p. 138.

(23) - Idem, Ibidem.

(24) - Lerner, Victoria, op. cit. p. 79.

(25) - Lerner, Victoria, op. cit., p. 76, llama la atención para este hecho citando a Rocheli, Abraham, Lázaro Cárdenas, Ideología y politica educativa 
terreno ideológico socialista con una desenvoltura sin similar en el panorama populista latino-americano.

Segun Octavio Ianni, en México la burguesia "Se acomoda a un estilo populista de gobierno, en el cual la rectórica a veces incluso socializante no altera fundamentalmente las relaciones capitalistas de producción ni las condiciones político-económicas de la acumulación de capital" (26).

La rectórica socialista de la burguesia mexicana es a una vez expresión de la seguridad de la condición hegemónica de esta clase social en la realidad política, económica y social de México en la época de Cárdenas y el puente que esta clase extende ideológicamente a las clases subalternas como si su Revolución fuera la de aquellas.

Todavia en 1945 Cárdenas volvía a utilizar este lenguaje, pero ahora con un poco más de precisión:

"La unidad nacional permanente, que permita vivir en franca armonia a todos los sectores, resulta imposible dentro de una democracia de tipo capitalista. Puede haber unidad por sectores en defensa de sus propios intereses pero no unidad nacional. Esto solo será posible cuando llegue a establecerse un sistema político-económico de carácter socialista" (27).

Pero, ahora el dirigente nacional-desarrollista que agilitó al capitalismo en su país, estructurando de forma definitiva al Estado capitalista post-Revolución ya hablaba sin las responsabilidades de jefe de Estado. Ya no era el comandante de la Revolución...

Por eso, la evolución histórica mexicana permitió que se dijera que la Revolución Mexicana fue la Revolución China que no se realizó, o permitirá la observación, también ya hecha, de tratarse del antecedente de la Revolución Rusa y de la Revolución China, ambas victoriosas. En verdad, la Revolución Mexicana tomó otros rumbos bien distintos y a partir de Lázaro Cárdenas quedó definitivamente concluída. Ella llegaba a la meta que esta nueva burguesia le había asignado.

(La Escuela Socialista), Tesis de doctorado, Faculdad de Ciencias Políticas y Sociales, UNAM, México, 1974, p. 250.

(26) - Ianni, Octavio, op. cit. p. 55.

(27) - Cárdenas, Lázaro, Obras, Apuntes II, México, UNAM, in: Herzog, Jesus Silva, Lázaro Cárdenas, Su pensamiento Económico, Social y Político, México, Nuestro Tiempo, 1975, p. 28. 
En Argentina y Brasil se podía postergar una atención específica a los campesinos. En México no. En México el control del Estado implicaba en una separación obrero-campesina. $\mathrm{Y}$ en relación a estos últimos, los campesinos, había que ir a su encuentro. Fue lo que Cárdenas y su grupo comprendieron y sintieron. Habia que eliminar el peligro potencial de la presencia campesina descontente. De cierta forma el "ir al encuentro" era una necesidad desde la perspectiva de esta burguesia ligada al proyecto de desarrollo nacional autónomo que igualaba a Cárdenas, Perón y Vargas, pero el "ir al encuentro" del campesinado - y su organización por separado de la de los obreros - era un factor disímil y de absoluta originalidad del caso mexicano.

El "ir al encuentro" tiene en sí la intención precípua del desarme de la potencialidad revolucionaria de las masas. Cárdenas sabe que las masas no son materia inerme de manipulación, sabe que hay que tenerlas en cuenta, el "ir al encuentro" significa realmente conceder. Es, por lo tanto, un acto anticipatorio, preventivo, una anticipación con finalidad armonizadora. Es una anticipación dentro del esperítu de su concepto de Unidad Nacional.

En ese sentido, el "ir al encuentro" es contrario al aplastamiento escueto a través del golpe de Estado, o la dictadura, sería el abandono, el olvido y la incapacidad e imposibilidad del "ir al encuentro". La obra de Cárdenas en la peculiar realidad mexicana, se reviste, entonces, de características más sólidas y duraderas que en Brasil y Argentina.

En cierta medida, Cárdenas englobó en su régimen y en la organización del Estado que realizó, las características del populismo en sus aspectos más "democráticos" y las características de las "dictaduras", como ocurren ambos los aspectos en el vasto panorama latinoamericano.

La estructuración del Estado quedó hecha de forma tan definitiva que la burguesia mexicana no necesitó valerse, más tarde, del golpe militar para mantener la autonomia del Estado burgués. Los elementos garantidores del Estado burgués que el golpe militar preserva en otros países de América Latina, ya estaban presentes en la estructuración de Estado cardenista .

Desde el punto de vista social, en una proyección hacia el futuro,

"la integración subordinada de los trabajadores y sus organizaciones al Estado constituye la base política y social en la cual se asienta la 
virtual conjelación de la lucha de clases que en el país se observa casi ininterrumpidamente desde entonces" (28).

El proyecto nacional cardenista se constituye en una realización duradera. Por otro lado, hay una preocupación exclusiva con la situación interna de México. Si bien Cárdenas se revele siempre un político atento a los acontecimientos internacionales y si bien frecuentemente tome partido de forma decidida o mismo brinde, no pocas veces, el apoyo de México a naciones o ativistas políticos, no hay en el caso cardenista, una preocupación de que su proyecto nacional pueda se revestir de características, o mismo, preocupaciones universales, con lo que confirma una característica de todas las revoluciones mexicanas, que es la de presentaren el nacionalismo como cerne ideológico. Las revoluciones de la Independencia, de Juárez, de 1910, son todas nacionales, nunca "bolivarianas". En Perón, por ejemplo, hay una nítida preocupación norteadora no solamente interna, pero también a nivel mundial. Cárdenas no eleva su régimen a una función rectora a nivel mundial como lo hace Perón, si bien que este aspecto del proyecto peronista parezca la evidencia reveladora de su fragilidad.

Así, la obra de estructuración Interna en el caso cardenista, no admitió afirmaciones grandiloquentes a nivel universal. La obra interna era absorvente y no había tiempo ni posibilidad para divagaciones que no estuvieran intrínsecamente ligadas a la meta inmediata y precípua, o sea, estructurar y organizar, con acabamientos de obra-prima, el Estado Nacional.

De esta forma, en el caso mexicano, gobernantes y gobernados empiezan a desarrollar sus relaciones dentro del mismo marco jurídico y político; cada elemento social empezó a desempeñar su papel por su cuenta, pero guardando siempre una estrecha relación con el Estado, y sobretodo, con el presidente. A partir de Cárdenas hay una identificación estrecha entre el jefe y el Estado, pero el poder duradero, la autoridad establecida es la del Estado. El papel carismático de los líderes está submetido a la realidad institucional. En México, el populismo se ha hecho sistema institucional.

(28) - Cordera, Rolando, Estado y Capitalismo tardío y subordinado, Investigación Económica, n⿳⺈ 123, México, 1971, p. 486. 